EPIDEMIOLOGY

\title{
Early growth and adult respiratory function in men and women followed from the fetal period to adulthood
}

\author{
Dexter Canoy, Juha Pekkanen, Paul Elliott, Anneli Pouta, Jaana Laitinen, Anna-Liisa Hartikainen, \\ Paavo Zitting, Swatee Patel, Mark P Little, Marjo-Riitta Järvelin
}

Thorax 2007;62:396-402. doi: 10.1136/thx.2006.066241

See end of article for authors' affiliations

Correspondence to: Dr Dexter Canoy, Northwest Institute for Bio-Health Informatics, The University of Manchester, Oxford Road, Manchester M13 9PT, UK; dexter.canoy@manchester. ac.uk

Received 29 May 2006

Accepted 9 October 2006

Published Online First

13 November 2006 Background: While some studies suggest that poor fetal growth rate, as indicated by lower birth weight, is
associated with poor respiratory function in childhood, findings among adults remain inconsistent. A study was undertaken to determine the association between early growth and adult respiratory function.

Methods: A longitudinal birth cohort study was performed of 5390 men and women born full term and prospectively followed from the fetal period to adulthood. Weight at birth and infancy were recorded, and forced expiratory volume in $1 \mathrm{~s}\left(\mathrm{FEV}_{1}\right)$ and forced vital capacity (FVC) were assessed by standard spirometry at age 31 years.

Results: Adult FEV 1 and FVC increased linearly with higher birth weight in both men and women with no apparent threshold. After adjustment for sex, adult height and other potential confounders operating through the life course, every $500 \mathrm{~g}$ higher birth weight was associated with a higher $\mathrm{FEV}$ of $53.1 \mathrm{ml}(95 \% \mathrm{Cl} 38.4$ to $67.7)$ and higher FVC of $52.5 \mathrm{ml}(95 \% \mathrm{Cl} 35.5$ to 69.4). These positive associations persisted across categories of smoking, physical activity and body mass index, with the lowest respiratory function noted among those with lower birth weight who were smokers, led a sedentary lifestyle or were overweight. Weight gain in infancy was also positively associated with adult lung function.

Conclusion: Birth weight is continuously and independently associated with adult respiratory function. It is plausible that poor growth in early life may restrict normal lung growth and development, which could have long-term consequences on lung function later in life.

C hildren born with lower birth weight tend to have poorer lung function than those of higher birth weight, ${ }^{1-4}$ although longitudinal data assessing the relation between birth weight and adult lung function are limited and findings have been conflicting. ${ }^{5-14}$ The apparent inconsistencies could be due to small sample sizes, biases associated with the retrospective collection of birth weight data, high proportion of persons lost to follow-up or lack of information on potential confounders and mediating factors that may operate through the life course.

As poor lung function in adulthood is consistently shown as an independent predictor of all-cause mortality and deaths due to respiratory and cardiovascular diseases, ${ }^{15}{ }^{16}$ identifying whether the influence of lower birth weight on impaired respiratory function extends to adulthood could have important clinical and public health implications. We examined the relation between birth weight as a marker of general fetal growth, growth in infancy and subsequent adult respiratory function assessed at age 31 years in a large population-based cohort of men and women prospectively followed from the fetal period to adulthood.

\section{METHODS}

\section{Participants and data collection}

Recruitment and data collection of the 1966 Northern Finland Birth Cohort (NFBC) have been described elsewhere. ${ }^{.7}$ Briefly, the original birth cohort consisted of offspring $(n=12058$ live births with birth weight $\geqslant 600 \mathrm{~g}, 94.5 \%$ born at $\geqslant 37$ gestational weeks) of all pregnant women in Northern Finland with expected deliveries in 1966. Women were recruited and baseline data were collected by questionnaire during routine prenatal health check at maternity health centres, with about $80 \%$ visiting the centres for the first time by the 16th gestational week. The course of the pregnancy and data on birth at the time of delivery (99\% in hospitals) were prospectively recorded. Growth data of the offspring were collected at approximately 1 year of age from child welfare centres which have been established as part of the comprehensive welfare health system in Finland since $1944 .^{18}$ Data on hospital admissions were obtained from hospital records and from the national hospital discharge register. Follow-up in 1997-8 consisted of questionnaires sent to all cohort members, as well as clinical examination of those living in Northern Finland or in the capital city area. ${ }^{19}$ The University of Oulu ethics committee approved the study and participants gave written informed consent.

\section{Early life variables}

Birth weight (to the nearest $10 \mathrm{~g}$ ) was measured immediately after birth. Gestational age at birth was computed as number of completed weeks from date of mother's last menstrual period to delivery. Weight was also measured around 12 months of age (mean 12.3, range 10-14 months); the weight gain during the first year was calculated by subtracting the birth weight from this value.

Mothers were classified as smokers if they smoked at least one cigarette per day during pregnancy, quitters if they smoked at any time during 12 months preceding but not during pregnancy, and non-smokers if they neither smoked from 12 months preceding nor during pregnancy. Prenatal social class was based on father's occupation $(I=$ professionals, $\mathrm{II}=$ skilled $\quad$ workers, $\quad \mathrm{III}=$ unskilled $\quad$ workers, and IV $=$ farmers) or mother's occupation if missing. Using International Classification of Diseases (ICD) 8th edition, we identified children admitted to hospitals with diagnoses of

Abbreviations: $\mathrm{BMI}$, body mass index; $\mathrm{FEV}_{1}$, forced expiratory volume in $1 \mathrm{~s} ; \mathrm{FVC}$, forced vital capacity 
Table 1 Characteristics of men and women in the 1966 Northern Finland Birth Cohort study

\begin{tabular}{|c|c|c|}
\hline Characteristics & $\begin{array}{l}\text { Men } \\
(n=2684)\end{array}$ & $\begin{array}{l}\text { Women } \\
(\mathrm{n}=2706)\end{array}$ \\
\hline \multicolumn{3}{|l|}{ Early life factors } \\
\hline Birth weight $(g)$ & $3592(512)$ & $3467(474)$ \\
\hline Weight gain during first year $(\mathrm{kg})^{*}$ & $7.0(1.1)$ & $6.5(1.1)$ \\
\hline Gestational age at birth (weeks) & $40.2(1.5)$ & $40.3(1.5)$ \\
\hline $\begin{array}{l}\text { \% Parental social class III and IV at } \\
\text { birth† }\end{array}$ & $47.5(n=222)$ & $40.9(n=220)$ \\
\hline$\%$ Mothers smoking during pregnancy & $13.3(n=349)$ & $12.3(n=324)$ \\
\hline \% Childhood respiratory infection $\ddagger$ & $6.7(n=181)$ & $5.0(n=135)$ \\
\hline \multicolumn{3}{|l|}{ Factors at age 31 years } \\
\hline $\mathrm{FEV}_{1}$ (I) & $4.54(0.62)$ & $3.41(0.47)$ \\
\hline FVC (I) & $5.48(0.75)$ & $4.02(0.55)$ \\
\hline $\mathrm{FEV}_{1}: \mathrm{FVC}$ ratio (\%) & $83.1(6.4)$ & $85.0(6.5)$ \\
\hline $\mathrm{FEV}_{1}(\%$ predicted $)$ & 99.2 (11.7) & $101.8(11.7)$ \\
\hline Height $(\mathrm{m})$ & $1.78(0.8)$ & $1.65(0.6)$ \\
\hline Weight (kg) & 80.2 (12.7) & $65.6(12.5)$ \\
\hline BMI $\left(\mathrm{kg} / \mathrm{m}^{2}\right)$ & $25.2(3.6)$ & $24.2(4.7)$ \\
\hline$\%$ Current cigarette smokers & $32.7(n=878)$ & $23.0(n=622)$ \\
\hline$\%$ Known asthma at 14 or 31 years§ & $8.3(n=223)$ & $10.5(n=284)$ \\
\hline $\begin{array}{l}\text { \% Known emphysema or chronic } \\
\text { bronchitis§ }\end{array}$ & $5.4(n=144)$ & $5.9(n=160)$ \\
\hline \% Low physical activity level & $42.9(n=1151)$ & $41.7(n=1129)$ \\
\hline$\%$ Social class III and IV** & $66.0(n=308)$ & $50.7(n=249)$ \\
\hline
\end{tabular}

$\mathrm{FEV}_{1}$, forced expiratory volume in $1 \mathrm{~s}$; FVC, forced vital capacity; BMI, body mass index.

Data presented as mean (SD) for all continuous variables.

${ }^{*}$ Measured between the 10th and 14th months; data available for 2262 men and 2295 women.

†Parental social class (III = unskilled/others, IV = farmers).

fHospital diagnosis of acute respiratory infection or pneumonia between 0 and 7 years.

\$Physician diagnosis.

- Participation in brisk activity of at least 20 minutes was less than twice a week.

**Adult social class (III = vocational, IV = no education beyond elementary school/unknown).

acute respiratory illness or pneumonia occurring up to age 7 years as, at these ages, respiratory infection has been associated with reduced adult respiratory function. ${ }^{20}$ We also identified participants who had physician-diagnosed asthma at age 14 years assessed from questionnaires sent to participants and parents in 1980.

\section{Adult variables}

In $1997,97 \%(\mathrm{n}=11637)$ of the cohort were alive, $7.4 \%$ of whom $(\mathrm{n}=856)$ were living abroad and $0.8 \%(\mathrm{n}=96)$ were untraceable. In 1997-8, those living in Northern Finland or the Helsinki area $(n=8463)$ were invited to a clinical examination conducted by trained nurses using a standardised procedure. Respiratory function was assessed by forced expiratory volume in $1 \mathrm{~s}\left(\mathrm{FEV}_{1}\right)$ and forced vital capacity (FVC) using a Vitalograph P-model spirometer (Vitalograph Ltd, Buckingham, UK) with a volumetric accuracy of $\pm 2 \%$ or $\pm 50 \mathrm{ml}$, whichever was greater. The spirometer was calibrated regularly using a l-litre precision syringe. The spirometric manoeuvre was performed three times but was repeated if the difference between two maximal readings was $>4 \%$. The highest $\mathrm{FEV}_{1}$ and FVC measurements were used. We also measured weight and height and calculated body mass index (BMI) as weight/height ${ }^{2}$; overweight was defined as BMI $\geqslant 25 \mathrm{~kg} / \mathrm{m}^{2}$. Participants were classified as having a high level of physical activity if they were engaged in brisk physical activities (causing some sweating and breathlessness) at least 2-3 times a week for at least 20 minutes at a time (the approximate minimum level of activity which could enhance either fitness or health $\left.{ }^{21}\right)$. Current smokers were defined as smoking cigarettes daily for at least a year, former smokers if they had previously smoked cigarettes but had stopped for at least 1 year, and never smokers if they had neither currently nor previously smoked cigarettes daily for at least a year. Adult social class was based on highest education attained at 31 years ( $\mathrm{I}=$ university degree, II = secondary or polytechnic school, $\mathrm{III}=$ vocational school, and IV = others, including unknown or no education after elementary school). We also noted any history of physician-diagnosed asthma and emphysema or chronic bronchitis.

\section{Statistical analysis}

A total of 6033 participants attended the clinical examination at age 31 years. Those with missing or inadequate spirometric findings $(n=153)$, those born at $<37$ weeks $(n=275)$ and women who were pregnant during the clinical assessment $(\mathrm{n}=216)$ were excluded. The remaining 5390 participants (2684 men, 2706 women) were included in the analyses.

The results for men and women were analysed separately. Multiple linear regression was used to estimate the difference in respiratory function per $500 \mathrm{~g}$ higher birth weight (1SD of birth weight $=497 \mathrm{~g}$ ) and per $1 \mathrm{~kg}$ higher weight gain during the first year (available for 2262 men and 2295 women; ISD of weight gain during the first year $=1.1 \mathrm{~kg}$ ). Covariates included gestational age at birth, adult height and adult weight, a history of acute respiratory infection or pneumonia in childhood, maternal smoking during pregnancy, parental social class at birth, and adult cigarette smoking, physical activity level and social class. As covariates we used gestational age and adult height and weight as continuous variables in the regression models. We also mutually adjusted for birth weight and weight gain during the first year. Mean $\mathrm{FEV}_{1}$ and FVC were calculated by tertile of birth weight stratified by tertile of weight gain during the first year or by adult smoking, physical activity or BMI.

Expected $\mathrm{FEV}_{1}$ was determined for men and women who were never smokers and without emphysema or chronic bronchitis using sex-specific regression with height as an explanatory variable and percentage predicted $\mathrm{FEV}_{1}$ ((actual $\mathrm{FEV}_{1} /$ expected $\left.\mathrm{FEV}_{1}\right) \times 100$ ) was calculated. We also calculated the ratio of $\mathrm{FEV}_{1}$ to FVC. Interactions between birth weight and weight gain during the first year, adult smoking, adult physical activity or adult BMI were assessed by analysis of variance. BMI was used to define overweight and for assessing interaction with other covariates. In our analyses of the $\mathrm{FEV}_{1}: \mathrm{FVC}$ ratio, the covariates used in the regression models were similar to those used in our separate analyses for $\mathrm{FEV}_{1}$ and FVC. However, we only adjusted for gestational age, maternal smoking during pregnancy, adult weight and adult physical activity in the multivariate regression models for predicted $\mathrm{FEV}_{1}$. Two-sided $\mathrm{p}$ values were used with $\mathrm{p}<0.05$ being considered statistically significant. Data were analysed using Stata V.8 statistical software (College Station, Texas, USA).

\section{RESULTS}

\section{Baseline characteristics of study participants}

Compared with the remaining cohort members born full term, the 5390 study participants had $80 \mathrm{~g}$ higher birth weight and 0.4 weeks longer gestational age at birth (both $p<0.001$ ) but did not differ significantly in weight gained during their first year $(p>0.05)$. The characteristics of the study participants are shown in table 1 (see table S1 in the online supplement for characteristics by birth weight quintile). Mean (SD) birth weight was 3592 (512) g in men and 3467 (474) g in women; mean (SD) weight gain during the first year was 7.0 (1.1) kg in men and 6.5 (1.1) kg in women. Respective mean (SD) values 
Table 2 Estimated difference in respiratory function, assessed at age 31 years, for every $500 \mathrm{~g}$ higher birth weight in 5390 men and women in the 1966 Northern Finland Birth Cohort study

\begin{tabular}{|c|c|c|c|}
\hline \multirow[b]{2}{*}{ Covariates adjusted for in regression models } & \multirow{2}{*}{$\frac{\mathrm{FEV}_{1}(\mathrm{ml})}{\beta(95 \% \mathrm{Cl})}$} & \multirow{2}{*}{$\frac{\text { FVC (ml) }}{\beta(95 \% \mathrm{Cl})}$} & \multirow{2}{*}{$\frac{\text { FEV }_{1}: \text { FVC ratio (\%) }}{\beta(95 \% \mathrm{Cl})}$} \\
\hline & & & \\
\hline \multicolumn{4}{|l|}{ Men $(n=2684)$} \\
\hline Unadjusted & $127.7(105.4$ to 150.1$)$ & $160.4(133.4$ to 187.5$)$ & $-0.11(-0.35$ to 0.12$)$ \\
\hline Height† at 31 years & $47.0(26.6$ to 67.4$)$ & $49.6(26.0$ to 73.2$)$ & $0.09(-0.16$ to 0.33$)$ \\
\hline 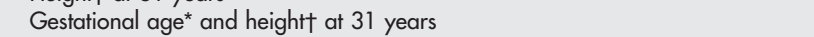 & $57.4(35.1$ to 79.7$)$ & $59.4(33.5$ to 85.2$)$ & $0.13(-0.14$ to 0.39$)$ \\
\hline Gestational age, ${ }^{*}$ maternal smoking during pregnancy and height† at 31 years & $54.6(32.1$ to 77.2$)$ & $57.8(31.6$ to 84.0$)$ & $0.10(-0.17$ to 0.37$)$ \\
\hline Gestational age, * maternal smoking during pregnancy and adult factorst‡ & $57.8(35.1$ to 80.4$)$ & $61.6(35.3$ to 88.0$)$ & $0.11(-0.16$ to 0.38$)$ \\
\hline Life course factors & 57.5 (34.9 to 80.1$)$ & $61.4(35.1$ to 87.7$)$ & $0.11(-0.16$ to 0.38$)$ \\
\hline Subgroup of men†§ $(n=1893)$ & $56.3(30.4$ to 82.3$)$ & $56.6(25.7$ to 87.5$)$ & $0.16(-0.14$ to 0.45$)$ \\
\hline \multicolumn{4}{|l|}{ Women $(n=2706)$} \\
\hline Unadjusted & $105.8(87.7$ to 123.9$)$ & $119.9(98.3$ to 141.4$)$ & $0.12(-0.14$ to 0.38$)$ \\
\hline Adjusted for height† at 31 years & $39.6(23.2$ to 56.1$)$ & $33.6(14.5$ to 52.6$)$ & $0.27(0.07$ to 0.54$)$ \\
\hline Adjusted for gestational age* and height† at 31 years & $45.5(27.8$ to 63.2$)$ & $41.0(20.7$ to 61.3$)$ & $0.26(-0.03$ to 0.54$)$ \\
\hline Gestational age, ${ }^{*}$ maternal smoking during pregnancy and height† at 31 years & $44.8(26.8$ to 62.9$)$ & $41.9(21.2$ to 62.6$)$ & $0.22(-0.07$ to 0.51$)$ \\
\hline Gestational age, ${ }^{*}$ maternal smoking during pregnancy and adult factorst† & 48.2 (30.0 to 66.4$)$ & $42.3(21.3$ to 63.2$)$ & $0.30(0.01$ to 0.60$)$ \\
\hline Life course factors & $48.8(30.3$ to 66.6$)$ & $42.3(21.3$ to 63.2$)$ & $0.31(0.01$ to 0.60$)$ \\
\hline Subgroup of women†£ $(n=1880)$ & 52.7 (31.2 to 74.3$)$ & 43.7 (19.1 to 68.2$)$ & $0.41(0.04$ to 0.77$)$ \\
\hline
\end{tabular}

FEV 1 , forced expiratory volume in $1 \mathrm{~s}$; FVC, forced vital capacity

*At birth.

†Excludes height as covariate for regression models for predicted $\mathrm{FEV}_{1}$.

$\ddagger$ Adult factors: height, weight, cigarette smoking (never, former and current) and physical activity level (high versus low) at 31 years.

- Gestational age at birth, maternal smoking during pregnancy, aforementioned adult factors as well as hospital diagnosis of respiratory infection between 0 and

7 years, other respiratory illnesses (physician diagnoses of asthma at age 14 or 31 years or emphysema/chronic bronchitis at 31 years), social class at birth (I, II, III and IV) and at age 31 years (I, II, III and IV).

$\S$ Excludes those with hospital diagnosis of respiratory infection between 0 and 7 years, whose mothers smoked during pregnancy and had physician-diagnosed asthma (at 14 or 31 years) or emphysema/chronic bronchitis at 31 years, and adjusted for gestational age at birth, aforementioned factors at 31 years and social class at birth (I, II, III and IV) and at age 31 years (I, II, III and IV).

for $\mathrm{FEV}_{1}$ in men and women were $4.54(0.62) \mathrm{l}$ and 3.41 (0.47) l, and for FVC were 5.48 (0.75) $\mathrm{l}$ and $4.02(0.55) \mathrm{l}$.
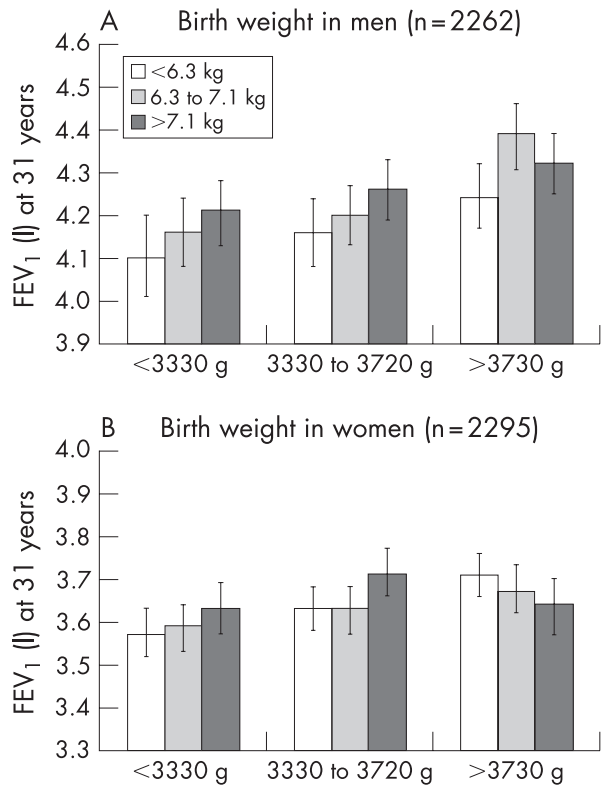

Figure 1 Forced expiratory volume in $1 \mathrm{~s}\left(\mathrm{FEV}_{1}\right)$ in litres at age 31 years by tertiles of birth weight and weight gain during the first year in $(A)$ men and (B) women in the 1966 Northern Finland Birth Cohort study. The figure shows mean values and $95 \%$ confidence limits. Values obtained from regression models and adjusted for gestational age at birth, maternal smoking during pregnancy and factors at 31 years: height, weight, cigarette smoking (never, former and current), and physical activity level (high versus low); $p$ value for interaction between birth weight and weight gain during the first year was 0.88 in men and 0.04 in women.

\section{Birth weight, weight gain at 1 year and respiratory function at age 31 years}

Respiratory function $\left(\mathrm{FEV}_{1}, \mathrm{FVC}\right.$ and \% predicted $\left.\mathrm{FEV}_{1}\right)$ linearly increased across the whole range of birth weight quintile ( $\mathrm{p}$ for trend $<0.001$ ) without any apparent threshold. Mean differences in respiratory function between top and bottom birth weight quintiles in men were $368 \mathrm{ml}\left(\mathrm{FEV}_{1}\right)$ and $459 \mathrm{ml}(\mathrm{FVC})$, and in women were $290 \mathrm{ml}\left(\mathrm{FEV}_{1}\right)$ and $314 \mathrm{ml}(\mathrm{FVC})$ (see table $\mathrm{Sl}$ in online supplement available at http://thorax.bmj.com/ supplemental). These mean differences reduced to $169 \mathrm{ml}$ (95\% CI 95 to 242) for $\mathrm{FEV}_{1}$ and $180 \mathrm{ml}$ (95\% CI 95 to 266) for FVC in men, and to $141 \mathrm{ml}(95 \% \mathrm{CI} 84$ to 198$)$ for $\mathrm{FEV}_{1}$ and $115 \mathrm{ml}$ (95\% CI 49 to 180) for FVC in women after adjusting for gestational age, maternal smoking during pregnancy and adult factors (height, cigarette smoking, weight and physical activity). The mean $\mathrm{FEV}_{1}$ :FVC ratio did not vary significantly across birth weight quintiles ( $p$ for trend $=0.56$ in men and 0.31 in women) (see table S1 in online supplement). After adjusting for the aforementioned covariates, a significant increasing trend across birth weight quintiles was observed only among women $(p=0.047)$. The magnitude of the difference in the adjusted mean $\mathrm{FEV}_{1}$ :FVC ratio between the top and lowest birth weight quintile was $0.4 \%$ ( $95 \%$ CI $-0.5 \%$ to $1.3 \%$ ) in men and $1.1 \%$ (95\% CI $0.2 \%$ to $2.0 \%$ ) in women. Adjusting for gestational age, maternal smoking during pregnancy and adult weight and physical activity, the difference in mean predicted $\mathrm{FEV}_{1}$ between the top and lowest birth weight quintile in men was $3.7 \%$ (95\% CI $2.1 \%$ to $5.2 \%$ ) and in women was $4.4 \%$ (95\% CI $2.8 \%$ to $6.0 \%$ ).

Both $\mathrm{FEV}_{1}$ and FVC were significantly higher for every $500 \mathrm{~g}$ higher birth weight (table 2), although the size of the coefficients was reduced by about half with adjustment for gestational age and adult height. The estimates remained significant with further adjustment for various potential confounders across the life course, even among relatively healthy men and women. Combining data for men and women and adjusting for sex, gestational age, maternal smoking during 
Table 3 Adjusted* regression of respiratory function (assessed at age 31 years) with birth weight and weight gain $†$ during the first year in men and women in the 1966 Northern Finland Birth Cohort study

\begin{tabular}{|c|c|c|c|c|}
\hline \multirow[b]{3}{*}{ Regression models } & \multirow{2}{*}{$\begin{array}{l}\text { Men (n= 2262) } \\
\mathrm{FEV}_{1}(\mathrm{ml})\end{array}$} & \multirow[b]{2}{*}{ FVC (ml) } & \multirow{2}{*}{$\frac{\text { Women }(\mathrm{n}=2295)}{\mathrm{FEV}_{1}(\mathrm{ml})}$} & \multirow[b]{2}{*}{$\mathrm{FVC}(\mathrm{ml})$} \\
\hline & & & & \\
\hline & $\beta(95 \% \mathrm{Cl})$ & $\beta(95 \% \mathrm{Cl})$ & $\beta(95 \% \mathrm{Cl})$ & $\beta(95 \% \mathrm{Cl})$ \\
\hline \multicolumn{5}{|l|}{ Model 1: } \\
\hline Birth weight (per $500 \mathrm{~g}$ ) & $60.5(35.1$ to 85.9$)$ & $64.4(35.2$ to 93.6$)$ & 54.1 (34.4 to 73.8$)$ & $47.3(24.8$ to 70.0$)$ \\
\hline \multicolumn{5}{|l|}{ Model 2: } \\
\hline Weight gain during first yeart (per $1 \mathrm{~kg}$ ) & $12.3(-10.1$ to 34.6$)$ & $41.8(16.1$ to 67.4$)$ & $12.0(-4.3$ to 28.4$)$ & 23.5 (4.9 to 42.0$)$ \\
\hline \multicolumn{5}{|l|}{ Model 3: } \\
\hline Birth weight (per $500 \mathrm{~g}$ ) & $63.7(38.1$ to 89.3$)$ & 72.4 (43.0 to 101.8 ) & 57.5 (37.6 to 77.4$)$ & $52.6(29.9$ to 75.3$)$ \\
\hline Weight gain during first yeart (per $1 \mathrm{~kg}$ ) & $20.1(-2.4$ to 42.5$)$ & 50.6 (24.8 to 76.4$)$ & $19.0(2.6$ to 35.4$)$ & $29.8(11.1$ to 48.5$)$ \\
\hline
\end{tabular}

pregnancy and other adult factors, every $500 \mathrm{~g}$ higher birth weight was associated with a higher $\mathrm{FEV}_{1}$ of $53.1 \mathrm{ml}(95 \% \mathrm{CI}$ 38.4 to 67.7 ) and a higher FVC of $52.5 \mathrm{ml}$ (95\% CI 35.5 to 69.4). A significant association between birth weight and $\mathrm{FEV}_{1}$ :FVC ratio was observed in women (but not in men) after adjusting for covariates. The estimated difference in predicted $\mathrm{FEV}_{1}$ for every 500 g higher birth weight was $1.3 \%$ (95\% CI $0.8 \%$ to $1.8 \%$ ) in men and $1.5 \%$ (95\% CI $1.0 \%$ to $2.0 \%$ ) in women after adjusting for gestational age at birth and adult factors (height, cigarette smoking, weight and physical activity). Adding a quadratic term for gestational age in the multivariate models used in table 2 did not materially alter the results.

Weight gain during first year was positively associated with lung function in men and women, with the regression coefficients increasing in magnitude when models were further adjusted for birth weight (table 3), although the confidence limits crossed the null association for $\mathrm{FEV}_{1}$ in men. Those in the lowest birth weight category who gained more weight in infancy tended to have higher $\mathrm{FEV}_{1}$ than those who gained less weight (fig l; see fig S1 in online supplement available at http:// thorax.bmj.com/supplemental for FVC results), although a statistically significant interaction between birth weight and weight gain during first year was only observed for $\mathrm{FEV}_{1}$ in women $(p=0.046)$. Women in the top birth weight tertile with higher weight gain during the first year tended to have lower lung function values.

A statistical interaction was observed between birth weight and sex for FVC $(p=0.007)$ but not for $\operatorname{FEV}_{1}(p=0.11)$ or $\mathrm{FEV}_{1}$ :FVC ratio $(\mathrm{p}=0.16)$. Similarly, a statistical interaction was observed between weight gain at 1 year and sex for FVC $(p=0.001)$, weakly for $\mathrm{FEV}_{1}(\mathrm{p}=0.067)$ but not for $\mathrm{FEV}_{1}: \mathrm{FVC}$ ratio $(\mathrm{p}=0.17)$.

\section{Birth weight, adult characteristics and respiratory function at age 31 years}

Higher $\mathrm{FEV}_{1}$ was noted with higher birth weight tertile across all categories of cigarette smoking, physical activity and BMI categories at age 31 years (fig 2; see fig S2 in online supplement available at http://thorax.bmj.com/supplemental for FVC results). Lowest values were observed among those in the bottom birth weight tertile who were smokers, had low physical activity level or were overweight. Participants with favourable profiles on these lifestyle variables but were at the lowest birth weight tertile had comparable, or even lower, $\mathrm{FEV}_{1}$ than those at the top birth weight tertile who were smokers, had lower physical activity level or were overweight. We did not observe any significant interaction between birth weight and these adult variables $(p>0.05)$ except in smoking for $\mathrm{FEV}_{1}(\mathrm{p}=0.03$ in men). The interactions between adult smoking and adult BMI for $\mathrm{FEV}_{1}$ and FVC in both men and women were not significant (all $\mathrm{p}>0.05$ ).

\section{DISCUSSION}

Respiratory function, assessed by $\mathrm{FEV}_{1}$ and $\mathrm{FVC}$ at age 31 years, increased linearly across the whole range of birth weight in both men and women with no apparent threshold. Weight gain during the first year was positively associated with adult lung function independently of birth weight. These observations suggest that respiratory health in adulthood could be influenced by growth early in life.

The association between early life measures such as weight at birth and infancy and respiratory function measured 31 years later could simply reflect the effect of height, an important determinant of respiratory function ${ }^{22}$ as lower birth weight babies tend to be shorter in stature later in life, ${ }^{23}$ but the present results were independent of adult height. The associations were independent of gestational age at birth, maternal smoking during pregnancy and childhood respiratory infections as well as known asthma or emphysema or chronic bronchitis in adulthood. The findings remained significant even after taking into account adult smoking habit, level of physical activity and weight as well as social class at birth and in adulthood. Indeed, the magnitude of the reduction in lung function was greatest among those who had a lower birth weight and were current smokers, led a sedentary lifestyle or were overweight. Although spirometric assessment can be influenced by voluntary effort, it seems unlikely that there would be systematic differences in spirometric performance with respect to early life growth.

Earlier studies evaluating the association between birth weight and respiratory function have focused on highly selected participants or studied outcomes in childhood ${ }^{1-4}$ when lung function has not reached the maximum potential. Few studies have assessed the relation between birth weight and lung function in adulthood, and the results have been inconsistent. Some studies have shown no association between birth weight and adult lung function, ${ }^{79^{12-14}}$ while others have found a positive relationship either with both $\mathrm{FEV}_{1}$ and $\mathrm{FVC}^{561011}$ or with FEV 1 but not FVC. ${ }^{5}$ Consistent with other studies, ${ }^{568}$ we found no trend in the $\mathrm{FEV}_{1}$ :FVC ratio across quintiles of birth weight, although we found a weak but significant association among women. This sex-related difference in the findings was due to the weaker association of birth weight with FVC than with $\mathrm{FEV}_{1}$ in women, whereas the associations of birth weight with both measures were of similar magnitude in men. 

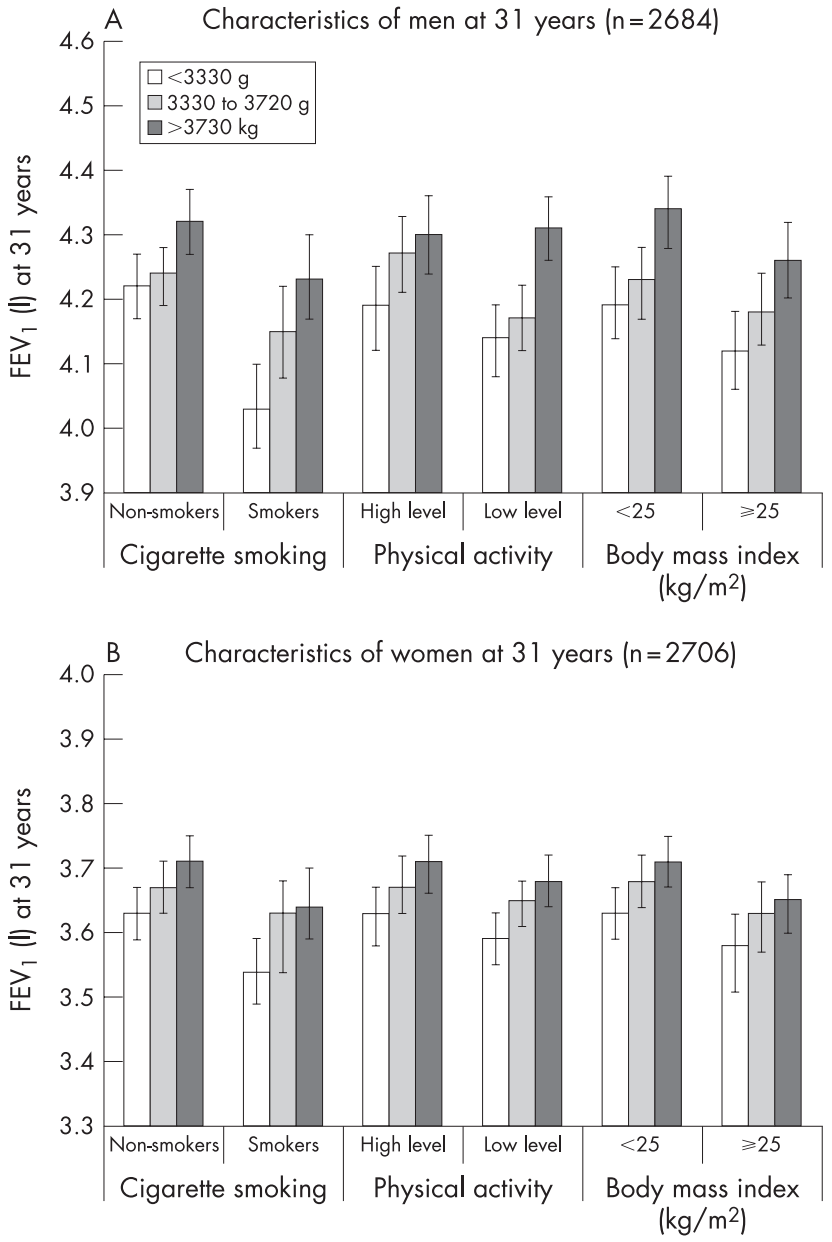

Figure 2 Forced expiratory volume in 1 second $\left(\mathrm{FEV}_{1}\right)$ in litres in $(\mathrm{A})$ men and (B) women at age 31 years by tertile of birth weight stratified by adult characteristics of men and women in the 1966 Northern Finland Birth Cohort study. The figure shows mean values and $95 \%$ confidence limits. Values obtained from regression models and adjusted for gestational age at birth, maternal smoking during pregnancy and factors at 31 years: height, weight, cigarette smoking (never, former and current) and physical activity level (high versus low) except for factor under consideration or weight for analysis using body mass index (weight/height ${ }^{2}$ ). Smokers were current smokers and non-smokers were never and former smokers combined. High physical activity level defined as participation in brisk activity of at least 20 minutes twice a week and low level if participation was less in duration and/or frequency per week. $p$ for interactions: birth weight and smoking (men $=0.03$, women $=0.31$ ), birth weight and physical activity $(\operatorname{men}=0.09$, women $=0.41)$, and birth weight and body mass index $(\operatorname{men}=0.54$, women $=0.30$ ).

Previous studies were limited by small sample size, ${ }^{6} 7^{9-11} 13$ use of self-reported birth weight, ${ }^{14}$ retrospectively obtained perinatal information or reliance on the availability of birth weight data from historical records..$^{5-811} 12$ Other limitations include loss to follow-up of participants, ${ }^{811}$ use of hospitalbased populations ${ }^{9}{ }^{10}$ and limited data for women ${ }^{5}$ or men. ${ }^{14}$ Our study was based on a large population-based cohort of men and women who were prospectively followed up from the fetal period to adulthood. Furthermore, our birth weight data were obtained immediately after birth, minimising errors associated with timing, inaccurate recall and rounding off of birth weight measurement.

These limitations could have important implications in determining the strength of the association between early growth and adult lung function. A meta-analysis of these studies suggested that $1 \mathrm{~kg}$ of birth weight was associated with an increase in $\mathrm{FEV}_{1}$ of $48 \mathrm{ml}$ (95\% CI 26 to 70) after adjusting for age, smoking and height. ${ }^{14}$ Using a similar regression model, a $1 \mathrm{~kg}$ change in birth weight in our cohort was associated with a difference in $\mathrm{FEV}_{1}$ of $96.1 \mathrm{ml}$ (95\% CI 55 to 137.2) in men and $80.0 \mathrm{ml}$ (95\% CI 47.0 to 113.2 ) in women (combined estimates for men and women after further adjustment for sex was $89.2 \mathrm{ml}$ (95\% CI 62.6 to 115.8$)$ ). Taking into account other factors through the life course suggests that these estimates might be slightly higher (table 2). The estimate in the metaanalysis may reflect non-random measurement errors which could have weakened the true association. Our findings suggest that the association between birth weight and adult lung function could be stronger than previously shown.

The effect of postnatal growth on adult lung function has been less well studied. It has been suggested that lower birth weight babies with higher postnatal weight gain may develop metabolic abnormalities and cardiovascular disease in adulthood. ${ }^{24}$ One study suggested that small babies who gained greater weight at 5-14 weeks had diminished infant lung function than those who gained less weight. ${ }^{25}$ In our cohort, postnatal weight gain among those in the lowest birth weight category was not associated with diminished adult lung function. Furthermore, anthropometric measures at birth and at 12 months among Chileans were unrelated to $\mathrm{FEV}_{1}$ measured in their late teens. ${ }^{26}$ Actual data were not presented in this paper, but we speculate that an age-related decline might heighten differences in lung function across the birth weight gradient. Alternatively, ethnicity might also play a role. In a non-Caucasian population, birth weight was reported to be unrelated to adult lung function. ${ }^{9}$

Pulmonary development runs in parallel with the stage of bodily development at birth. ${ }^{27}{ }^{28}$ In humans, lung development continues postnatally with airway and alveolar formation and enlargement mainly continuing up to 2 years of age. ${ }^{28}{ }^{29}$ As fetal life is a period of rapid growth, any stimulus or insult at this critical period of early life development could permanently alter or "programme" the structure and physiology of the respiratory system with possible long-term consequences. ${ }^{30}$ Lower birth weight could indicate the effect of an adverse intrauterine environment which retards growth in utero and consequently constrains growth of the airways and peripheral lung development. Since alveolar development continues into early infancy, impaired postnatal growth could also restrict further lung growth and differentiation.

The mechanism linking fetal growth retardation and impaired lung development is unclear. Maternal smoking during pregnancy is associated with lower birth weight, ${ }^{31}$ impaired lung function in infancy ${ }^{32}$ and childhood, ${ }^{33}$ and higher lung function decline in young adulthood. ${ }^{34}$ Although our findings were independent of maternal smoking during pregnancy, other factors such as maternal nutrition during pregnancy could play a role. ${ }^{29}$ In animals, impairment in airway development has accompanied intrauterine growth restriction due to undernutrition..$^{35}$ Intrauterine growth restriction, which could also be due to excess fetal exposure to exogenous adrenocortical hormones, ${ }^{37}$ is associated with raised fetal cortisol levels. ${ }^{38}$ Prolonged early life exposure to glucocorticoids could have adverse affects on lung morphometry and alveolarisation..$^{39}$ Fetal growth retardation in itself may restrict lung distension, an important physical factor known to stimulate fetal lung growth. ${ }^{40}$ Lower birth weight has been associated with a lower proportion of lean mass ${ }^{41}$ and lower muscular strength, ${ }^{42}$ possibly affecting the muscular component of ventilation. As low birth weight has been associated with diminished lung function in infancy ${ }^{4}$ and in childhood, ${ }^{1-3}$ and pulmonary function has been shown to track in childhood and 
adolescence to adulthood, ${ }^{43}$ it is plausible that the reduced adult lung function in lower birth weight babies reflects their failure to achieve maximum adult ventilatory capacity. Although our cohort is still mainly too young to develop important clinical outcomes such as chronic obstructive pulmonary disease, diminished lung function in young adulthood could render them at higher risk of developing chronic obstructive airway disease later in life. ${ }^{5}$

Our study has certain limitations. We did not assess lung function serially over time, although a single measurement of pulmonary function in adulthood has consistently been shown to predict important health outcomes in different populations. ${ }^{15}{ }^{16}$ Further, the relatively increased age-related decline in pulmonary function is normally observed in the late 30 s, so our estimates are probably more stable and less affected by these rapid changes. ${ }^{44}$ However, we may not be able to assess changes over time separately for $\mathrm{FEV}_{1}$ and $\mathrm{FVC}$ which might have implications in interpreting the age-related or sex-specific decline in the $\mathrm{FEV}_{1}: \mathrm{FVC}$ ratio. ${ }^{44}$ Reversibility of airflow limitation was not examined, but we have previously shown that birth weight is unrelated to asthma or skin atopy. ${ }^{45}$ We also cannot rule out a common underlying genetic explanation for fetal growth retardation and reduced adult lung function. On the other hand, an important strength of the study is that we were able to include prospectively collected data on potential confounders and mediating factors operating throughout the life course.

In conclusion, babies with lower birth weight and poor infant growth may be at a higher risk for developing impaired adult pulmonary function. Our findings suggest that impaired respiratory function may be preventable or modifiable through the life course by targeting better maternal health during pregnancy, improved nutrition in infancy and adopting a healthy lifestyle in adulthood.

\section{ACKNOWLEDGEMENTS}

The authors thank the participants and staff for their continued cooperation with the study. They also acknowledge the database management support of Mr Markku Koiranen (University of Oulu) and Ms Ulla Sovio (Imperial College London), and statistical advice from $\mathrm{Mr}$ Jari Jokelainen (University of Oulu), Professor Nicholas Day (University of Cambridge) and Dr Anne-Helen Harding (University of Cambridge).

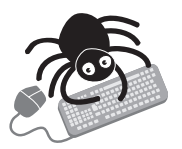

Further data are available in table $\mathrm{S} 1$ and figs $\mathrm{S} 1$ and S2 available online at http://thorax.bmj.com/supplemental

\footnotetext{
Authors' affiliations

Dexter Canoy, Paavo Zitting, Department of Public Health Science and General Practice, University of Oulu, Finland

Paul Elliott, Mark P Little, Mario-Riitta Järvelin, Department of

Epidemiology and Public Health, Imperial College London, UK

Juha Pekkanen, Environmental Epidemiology Unit, National Public Health Institute, Finland

Anneli Pouta, Department of Child and Adolescent Health, National Public Health Institute, Finland

Anna-Liisa Hartikainen, Department of Obstetrics and Gynecology, University of Oulu, Finland

Jaana Laitinen, Oulu Regional Institute of Occupational Health, Finland Swatee Patel, School of Computing and Mathematical Sciences, The University of Greenwich, UK

The 1966 Northern Finland Birth Cohort study has been supported by programme grants from the Academy of Finland, the University of Oulu and the University Hospital Oulu. Additional grants were received from the European Commission (Quality of Life and Management of Living Resources Programme, contract number QLG1-CT-2000-01643) for data collection. Funding agencies were not involved in the study design, analysis
}

and data interpretation, writing of the manuscript, and the decision to submit the paper for publication.

Competing interests: None declared

\section{REFERENCES}

1 Chan KN, Noble-Jamieson CM, Elliman A, et al. Lung function in children of low birth weight. Arch Dis Child 1989;64:1284-93.

2 Rona RJ, Gulliford MC, Chinn S. Effects of prematurity and intrauterine growth on respiratory health and lung function in childhood. BMJ 1993;306:817-20.

3 Doyle LW, Cheung MM, Ford GW, et al. Birth weight $<1501 \mathrm{~g}$ and respiratory health at age 14. Arch Dis Child 2001:84:40-4.

4 Dezateux C, Lum S, Hoo AF, et al. Low birth weight for gestation and airway function in infancy: exploring the fetal origins hypothesis. Thorax 2004;59:60-6.

5 Barker DJ, Godfrey KM, Fall C, et al. Relation of birth weight and childhood respiratory infection to adult lung function and death from chronic obstructive airways disease. BMJ 1991;303:671-5.

6 Stein CE, Kumaran K, Fall CH, et al. Relation of fetal growth to adult lung function in south India. Thorax 1997;52:895-9.

7 Shaheen SO, Sterne JA, Tucker JS, et al. Birth weight, childhood lower respiratory tract infection, and adult lung function. Thorax 1998;53:549-53.

8 Lopuhaa CE, Roseboom TJ, Osmond C, et al. Atopy, lung function, and obstructive airways disease after prenatal exposure to famine. Thorax 2000;55:555-61

9 Cheung YB, Karlberg JP, Low L, et al. Birth weight and adult lung function in China. Thorax 2001;56:85.

10 Boezen HM, Vonk JM, van Aalderen WM, et al. Perinatal predictors of respiratory symptoms and lung function at a young adult age. Eur Respir $J$ 2002;20:383-90.

11 Edwards CA, Osman LM, Godden DJ, et al. Relationship between birth weight and adult lung function: controlling for maternal factors. Thorax 2003;58:1061-5.

12 Laerum BN, Svanes C, Gulsvik A, et al. Is birth weight related to lung function and asthma symptoms in Nordic-Baltic adults? Respir Med 2004;98:61 1-8.

13 Matthes JW, Lewis PA, Davies DP, et al. Birth weight at term and lung function in adolescence: no evidence for a programmed effect. Arch Dis Child 1995;73:231-4.

14 Lawlor DA, Ebrahim S, Davey SG. The association of birth weight with adult lung function: findings from the British Women's Heart and Health Study and a metaanalysis. Thorax 2005;60:851-8.

15 Sin DD, Wu L, Man SF. The relationship between reduced lung function and cardiovascular mortality: a population-based study and a systematic review of the literature. Chest 2005;127:1952-9.

16 Mannino DM, Buist AS, Petty TL, et al. Lung function and mortality in the United States: data from the First National Health and Nutrition Examination Survey follow up study. Thorax 2003;58:388-93.

17 Rantakallio $\mathbf{P}$. The longitudinal study of the northern Finland birth cohort of 1966. Paediatr Perinat Epidemiol 1988;2:59-88.

18 Valvanne L. Kansanomaisesta synnytysavusta tämänpäivän äityishuoltoon [From traditional neighbour-aid during delivery to present-day maternity welfare]. Suomen Lääkärilehti [Finnish Medical Journal] 1966;21:1807-20.

19 Jarvelin MR, Sovio U, King V, et al. Early life factors and blood pressure at age 31 years in the 1966 Northern Finland birth cohort. Hypertension 2004:44:838-46.

20 Johnston ID, Strachan DP, Anderson HR. Effect of pneumonia and whooping cough in childhood on adult lung function. N EnglJ Med 1998;338:581-7.

21 American College of Sports Medicine. The recommended quantity and quality of exercise for developing and maintaining cardiorespiratory and muscular fitness, and flexibility in healthy adults. Med Sci Sports Exerc 1998;30:975-91.

22 Quanjer PH, Tammeling GJ, Cotes JE, et al. Lung volumes and forced ventilatory flows. Report Working Party Standardization of Lung Function Tests, European Community for Steel and Coal. Official Statement of the European Respiratory Society. Eur Respir J 1993;16(Suppl):5-40.

23 Sorensen HT, Sabroe S, Rothman KJ, et al. Birth weight and length as predictors for adult height. Am J Epidemiol 1999;149:726-9.

24 Singhal A, Lucas A. Early origins of cardiovascular disease: is there a unifying hypothesis? Lancet 2004;363:1642-5.

25 Lucas JS, Inskip HM, Godfrey KM, et al. Small size at birth and greater postnatal weight gain: relationships to diminished infant lung function. Am J Respir Crit Care Med 2004; 170:534-40.

26 Rona RJ, Smeeton NC, Bustos $P$, et al. The early origins hypothesis with an emphasis on growth rate in the first year of life and asthma: a prospective study in Chile. Thorax 2005;60:549-54.

27 Engel S. The structure of the respiratory tissue in the newly-born. Acta Anat (Basel) 1953;19:353-65.

28 Becklake MR, Kauffmann F. Gender differences in airway behaviour over the human life span. Thorax 1999;54:1119-38.

29 Merkus PJ, Have-Opbroek AA, Quanjer PH. Human lung growth: a review. Pediatr Pulmonol 1996;21:383-97.

30 Lucas A. Programming by early nutrition in man. The childhood environment and adult disease. Chichester, UK: John Wiley, 1991:38-55.

31 Rantakallio $\mathbf{P}$. The effect of maternal smoking on birth weight and the subsequent health of the child. Early Hum Dev 1978;2:371-82.

32 Lodrup Carlsen KC, Jaakkola JJ, Nafstad P, et al. In utero exposure to cigarette smoking influences lung function at birth. Eur Respir J 1997;10:1774-9.

33 Cunningham J, Dockery DW, Speizer FE. Maternal smoking during pregnancy as a predictor of lung function in children. Am J Epidemiol 1994; 139:1 139-52. 
34 Jaakkola MS, Ernst P, Jaakkola JJ, et al. Effect of cigarette smoking on evolution of ventilatory lung function in young adults: an eight year longitudinal study. Thorax 1991;46:907-13.

35 Wignarajah D, Cock ML, Pinkerton KE, et al. Influence of intrauterine growth restriction on airway development in fetal and postnatal sheep. Pediatr Res 2002;51:681-8.

36 Kelsen SG, Ference M, Kapoor S. Effects of prolonged undernutrition on structure and function of the diaphragm. J Appl Physiol 1985;58:1354-9.

37 Reinisch JM, Simon NG, Karow WG, et al. Prenatal exposure to prednisone in humans and animals retards intrauterine growth. Science 1978;202:436-8.

38 Seckl JR. Glucocorticoid programming of the fetus: adult phenotypes and molecular mechanisms. Mol Cell Endocrinol 2001;185:61-71.

39 Jobe AH. Glucocorticoids, inflammation and the perinatal lung. Semin Neonatol $2001 ; 6: 331-42$.
40 Kitterman JA. Physiological factors in fetal lung growth. Can J Physiol Pharmacol 1988;66:1122-8.

41 Singhal A, Wells J, Cole TJ, et al. Programming of lean body mass: a link between birth weight, obesity, and cardiovascular disease? Am J Clin Nutr 2003;77:726-30.

42 Kuh D, Bassey J, Hardy R, et al. Birth weight, childhood size, and muscle strength in adult life: evidence from a birth cohort study. Am J Epidemiol 2002; 156:627-33.

43 Twisk JW, Staal BJ, Brinkman MN, et al. Tracking of lung function parameters and the longitudinal relationship with lifestyle. Eur Respir J 1998;12:627-34.

44 Burrows B, Cline MG, Knudson RJ, et al. A descriptive analysis of the growth and decline of the FVC and FEV 1 . Chest 1983;83:717-24.

45 Pekkanen J, Xu B, Jarvelin MR. Gestational age and occurrence of atopy at age 31 : a prospective birth cohort study in Finland. Clin Exp Allergy 2001;31:95-102.

\section{LUNG ALERT}

\section{Pulmonary alveolar proteinosis: revealing a wider defect in host immunity}

$\Delta$ Uchida K, Beck DC, Yomamoto T, et al. GM-CSF autoantibodies and neutrophil dysfunction in pulmonary alveolar proteinosis. NEJM 2007;356:567-79.

$\mathrm{P}$ ulmonary alveolar proteinosis (PAP) is a rare disorder of excessive accumulation of surfactant components in alveoli. The inhibition of granulocyte-macrophage colonystimulating factor (GM-CSF) by blocking autoantibodies seems to lead to impaired surfactant clearance by alveolar macrophages. The authors explored the hypothesis that common and opportunistic pulmonary and disseminated infections reported in PAP are secondary to the effect of GM-CSF autoantibody (GM-CSF-Ab) on neutrophils by studying measures of neutrophil function.

In this prospective case-control study, neutrophils from five groups ( 12 subjects with PAP, 61 healthy controls, 12 patients with either cystic fibrosis (CF) or end-stage liver disease, 5 GMCSF-/- mice (both alleles of the GM-CSF gene disabled) and 5 wild mice) were initially assessed using neutrophil count, ultra-structure and function. Both basal (cellular adhesion, basal phagocyte index, phagocyte capacity and oxidative burst) and GM-CSF primed neutrophil function (phagocytic capacity) and blood level of CDllb (a GM-CSF stimulated adhesion molecule promoting neutrophil-vascular endothelial adhesion) were measured. Basal and primed neutrophil functions were re-measured following incubation with GM-CSF-Ab in a dosedependent fashion.

Neutrophil number and ultra-structure were similar in all groups. PAP cases had significantly low basal and GM-CSF augmented neutrophil functions. GM-CSF-/- mice had reduced basal but normal augmented neutrophil function. Patients with CF or end-stage liver disease had normal basal and augmented neutrophil function. The functions of normal human and wild mice neutrophils were reduced in a dose-dependent manner after incubating them with GM-CSF-Ab derived from PAP cases and mice, respectively.

The study provides support to the role of GM-CSF in the treatment of PAP. However, the absence of repeated lung infection is surprising given the magnitude of neutrophil defect in vitro. Minimal interstitial inflammation /fibrosis in PAP, possibly linked to reduced neutrophil function, may also raise the important question of whether monoclonal GM-CSF-Ab could be of use in diseases with excessive neutrophil activation like neutrophilic asthma and CF.

Samudra Mukheriee Specialist Registrar, Department of Paediatrics, Basildon \& Thurrock University Hospital NHS Foundation Trust, UK; samudra@doctors.org.uk 